\title{
CONSERVAÇÃO DE SEMENTES DE CAFÉ (Coffea arabica L.) DESPOLPADO E NÃO DESPOLPADO ${ }^{1}$
}

\author{
ROBERTO FONTES ARAUJO', EDUARDO FONTES ARAUJO², \\ PAULO ROBERTO CECON ${ }^{3}$, VALDINEI SOFIATTI ${ }^{4}$
}

\begin{abstract}
RESUMO - O presente trabalho foi conduzido no Laboratório de Pesquisa em Sementes da Universidade Federal de Viçosa com objetivo de estudar o efeito de diferentes materiais (sementes com 48-49, 31-32, 18-19 e 13-14\% de umidade e frutos), embalagens (permeável e impermeável) e ambientes de armazenamento (temperaturas de 7,15 e $25^{\circ} \mathrm{C}$ ) na conservação de sementes de café arábica, cultivar Catuai IAC 44. Para tanto, após a colheita dos frutos no estádio cereja foi retirada uma amostra e o restante despolpado mecanicamente e as sementes degomadas por fermentação natural durante 24 horas. Para atingir os graus de umidade desejados as sementes foram submetidas à secagem a sombra e em estufa com ventilação forçada. Em seguida, os materiais (sementes com diferentes graus de umidade e os frutos recém colhidos) foram tratados quimicamente, acondicionados nas duas embalagens e armazenados em ambientes com diversas temperaturas. Antes (mês zero) e após três, seis e nove meses de armazenamento, os frutos restantes foram despolpados e as sementes de todos os tratamentos avaliadas quanto a germinação e vigor (envelhecimento acelerado e comprimento de radícula), além da determinação do grau de umidade. Pelos resultados obtidos verificou-se que as sementes conservaram-se melhor quando armazenadas com 18,5\% de umidade, em ambiente de baixa temperatura $\left(7^{\circ} \mathrm{C}\right)$, independente da embalagem. Sementes com $31,5 \%$ de umidade também podem ser armazenadas por nove meses, a $7^{\circ} \mathrm{C}$, quando acondicionadas em embalagem permeável. Com umidade ainda mais elevada $(48,5 \%)$, as sementes conservaram-se bem até o sexto mês de armazenamento quando acondicionadas em embalagem permeável e em temperatura de $15^{\circ} \mathrm{C} . \mathrm{O}$ armazenamento de frutos em diferentes temperatura e de sementes a $25^{\circ} \mathrm{C}$ promove queda drástica na germinação e no vigor de sementes de cafeeiro, já aos três meses de armazenamento.
\end{abstract}

Termos para indexação: umidade, embalagem, fruto, estádio cereja, desidratação, armazenamento.

\section{SEED CONSERVATION OF DEPULPED AND NON-DEPULPED COFFEE (Coffea arabica L.)}

\begin{abstract}
This work was conducted at the Seed Research Laboratory of the Universidade Federal de Viçosa to study the effect of different materials (coffee seeds with 48-49, 31-32, 18-19 and 13 $14 \%$ of moisture and coffee fruits), types of packaging (permeable and impermeable) and storage environments (temperatures at 7,15 and $25^{\circ} \mathrm{C}$ ) on conservation of arabica coffee seeds, cultivar Catuai IAC 44 . Thus, after harvest of the fruits at the cherry stage a sample was collected, and the remaining fruit was mechanically depulped and the seeds submitted to natural fermentation for 24 hours. To reach the degree of moisture desired, the seeds were submitted to shade drying and oven drying with forced ventilation. The materials (seeds displaying different degrees of moisture and recently-collected
\end{abstract}

${ }^{1}$ Submetido em 25/04/2007. Aceito em 06/05/2008.

Parte da dissertação de mestrado do primeiro autor apresentada à Universidade Federal do Rio Grande do Sul (UFRGS).

2Engenheiro Agrônomo, MSc, UFRGS, jornadajb@ig.com.br
${ }^{3}$ Engenheiro Agrônomo, Dr., professor adjunto, Departamento de Plantas Forrageiras e Agrometeorologia (DPFA), UFRGS, Av Bento Gonçalves, 7712, Bairro Agronomia, Cep. 91.540-000, Porto Alegre, RS, Brasil.

${ }^{4}$ Professor aposentado, colaborador convidado, DPFA, UFRGS. 
fruits) were chemically treated, placed in two packing bags and stored at several temperatures. Before (month zero) and after three, six, and nine months of storage, the remaining fruits were depulped and the seeds in all treatments were evaluated for germination and vigor (accelerated aging and radicle), as well as moisture degree determination. The results obtained showed that conservation was better when the seeds were stored at $18.5 \%$ moisture, at a low temperature environment $\left(7^{\circ} \mathrm{C}\right)$, regardless of type of packaging. Seeds with $31.5 \%$ moisture can also be stored for 9 months, at $7^{\circ} \mathrm{C}$, when packed in permeable bags. At even higher humidity (48.5\%), good coffee seed conservation was observed until the sixth month of storage when permeable bags were used and at temperature of $15^{\circ} \mathrm{C}$. It was also verified that, in all treatments in which fruits were stored at several temperatures and seeds were stored at $25^{\circ} \mathrm{C}$, there was a drastic drop in germination and vigor in the third month of storage.

Index terms: moisture, packaging, fruit, cherry stage, dehydration, storage.

\section{INTRODUÇÃO}

As divisas geradas com a exportação e a mão-de-obra empregada nas diferentes etapas de produção fazem do café uma cultura de indiscutível importância sócio-econômica para o País.

A instalação do cafezal é realizada por intermédio de mudas obtidas pelo semeio de sementes. Desta forma, a utilização de sementes de alta qualidade fisiológica e com elevado desempenho germinativo, tem sido considerada como um dos principais fatores responsáveis pela obtenção de mudas mais vigorosas em condições de campo, resultando em maior produtividade.

A manutenção da qualidade das sementes de café durante o armazenamento é uma das maiores preocupações dos produtores de sementes, uma vez que elas perdem rapidamente a viabilidade, não conservando o poder germinativo em níveis satisfatórios por períodos superiores a seis meses após a colheita. Isso também limita a semeadura a um curto espaço de tempo, concentrando a obtenção de mudas em épocas que nem sempre são as mais apropriadas para o plantio.

O domínio de técnicas de conservação das sementes é de grande importância para a cafeicultura, pois permitirá o semeio para a produção de mudas em ocasião mais adequada. A conservação das sementes por mais de um ano também é desejável, pois além de poder preservar estoques genéticos, garante a manutenção de estoques reguladores para o atendimento de necessidades inesperadas, como no caso de geadas antes da colheita.

Os resultados dos trabalhos com sementes de café são contraditórios, não havendo definição das condições ideais para seu armazenamento. Diversos estudos têm demonstrado que a principal causa da rápida perda do poder germinativo é a grande sensibilidade destas sementes à desidratação (Bacchi, 1955 e 1956; Roberts, 1973 e Ellis et al., 1990).

Para alguns autores, sementes de café requerem valores relativamente altos no seu grau de umidade para a conservação. Silva \& Dias (1985) observaram que, após 10 meses de armazenamento, sementes com umidade entre 36 e $40 \%$ conservaram-se melhor. Resultados semelhantes foram obtidos por Vossen (1979), Barboza \& Herrera (1990) e Vasconcelos et al. (1992), os quais demonstraram que as sementes de café se conservaram melhor com graus de umidade de 41, 40 e 35\%, respectivamente. Entretanto, segundo Miglioranza (1982), sementes de café com alto grau de umidade perderam a viabilidade após seis meses de armazenamento, e aquelas com grau de umidade entre 8 e 10\% apresentaram, no final de 12 meses, 90\% de germinação.

Um fator importante que interage com o grau de umidade das sementes na conservação de sua qualidade fisiológica é o tipo de embalagem utilizado, que pode controlar ou não a troca de água da semente com o meio exterior. Bendanã (1962) observou que sementes de café mantiveram o seu poder germinativo em $95 \%$, durante quatro anos, quando acondicionadas em embalagem plástica a $10^{\circ} \mathrm{C}$ e $50 \%$ de umidade relativa do ar. Já Vossen (1979) afirmou que o armazenamento de sementes de café foi bem sucedido, por até 2,5 anos, quando estas foram mantidas em sacos de polietileno hermeticamente fechados e com a umidade de $41 \%$, a uma temperatura de $15^{\circ} \mathrm{C}$. Porém, quando se armazenou sementes com $35 \%$ de umidade, a $10^{\circ} \mathrm{C}$, ocorreu rápida perda da viabilidade.

Araújo (1988) armazenou sementes de Coffea arabica cv. Mundo Novo com 48,3, 21,6, 15,8, 13,1 e 8,9\% de umidade, em sacos de pano e de polietileno, em câmara fria $\left(3-4^{\circ} \mathrm{C}\right.$ e $80-85 \%$ de UR) e em condições não controladas de laboratório. Verificou que o melhor tratamento foi o de 
sementes com 48,3\% de umidade inicial, em saco de pano e em condições de laboratório, enquanto que, em sacos de polietileno, os melhores resultados foram sempre obtidos com sementes com baixo grau de umidade. Por outro lado, Dias \& Barros (1993) observaram que sementes de $C$. arabica acondicionadas em sacos de polietileno perfurado perderam totalmente o poder germinativo em 11 meses, apresentando ao final deste período $22 \%$ de umidade, enquanto que aquelas acondicionadas em saco de papel, em aproximadamente, dez meses, quando apresentavam 14\% de umidade final. Observaram, ainda, que o saco de polietileno lacrado foi a mais eficiente das embalagens, visto que, após 11 meses de armazenamento as sementes apresentaram $60 \%$ de germinação e mantiveram o grau de umidade inicial, de aproximadamente $37 \%$.

Baseado nessas considerações verifica-se grande controvérsia no que diz respeito ao grau de umidade das sementes, tipo de embalagem e condições do ambiente de armazenamento mais adequados para a preservação da viabilidade de sementes de café. Também, não foi encontrado na literatura estudos sobre armazenamento utilizando-se o fruto no estádio cereja, não despolpado, como uma maneira de se tentar a conservação da viabilidade de sementes de café.

O presente trabalho teve como objetivo estudar o efeito do fruto, do grau de umidade, do tipo de embalagem e da temperatura de armazenamento na conservação de sementes de café arábico, cultivar Catuaí IAC 44.

\section{MATERIAL E MÉTODOS}

O trabalho foi conduzido no Laboratório de Pesquisa em Sementes, da Universidade Federal de Viçosa (UFV), utilizando-se sementes de Coffea arabica L., cultivar Catuai IAC 44, provenientes de frutos maduros, no estádio cereja, colhidos manualmente, em maio de 2003. O campo de produção de sementes está localizado na Fazenda Experimental do Vale do Piranga, da Empresa de Pesquisa Agropecuária de Minas Gerais (EPAMIG), no município de Oratórios - MG, a 430m de altitude e coordenadas geodésicas $20^{\circ} 27^{\prime} 17^{\prime \prime}$ de latitude sul e $42^{\circ} 48^{\prime} 13^{\prime \prime}$ ' de longitude oeste, com uma área de $1,27 \mathrm{ha}$, possuindo 5.687 plantas matrizes de 16 anos de idade.

Imediatamente após a colheita, foi retirada uma amostra de frutos, que foram lavados e secados superficialmente, para formar um dos tratamentos do experimento. O restante dos frutos foi despolpado mecanicamente e as sementes degomadas por fermentação natural durante 24 horas, e, em seguida, lavadas em água corrente, eliminando-se as mais leves. Com a finalidade de retirar o excesso de umidade, as sementes foram colocadas em peneiras com malhas de náilon, à sombra. Realizou-se também a catação manual para eliminar as sementes defeituosas e sem pergaminho, os frutos inteiros, as cascas e outras impurezas. Posteriormente, foi realizado o expurgo das sementes com fosfina (três pastilhas por $\mathrm{m}^{3}$ durante 72 horas), visando o controle da broca do café e do caruncho das tulhas.

Para atingir os graus de umidade desejados, as sementes foram submetidas à secagem à sombra, durante 18 dias, até valor próximo de $19 \%$, e em estufa com ventilação forçada, para complementação da secagem, tomando-se o cuidado para que a temperatura não ultrapassasse $38^{\circ} \mathrm{C}$. Utilizouse o determinador de umidade Steinlite para auxiliar no acompanhamento da umidade das sementes, obtendo-se, pelo método de estufa, os seguintes valores: 48-49, 31-32, $18-19$ e $13-14 \%$ em base úmida. A umidade dos frutos era de aproximadamente $53 \%$.

Após a secagem até os graus de umidade desejados, as sementes e a amostra de frutos foram tratadas quimicamente com Dithane ( $2 \%$ em suspenção) e Malagran ( $1 \mathrm{~g}$ por $\mathrm{kg}$ de sementes). Em seguida, amostras de $500 \mathrm{~g}$ de sementes e de $6 \mathrm{~kg}$ de frutos foram acondicionadas em embalagens permeáveis (sacos de pano de algodão) e impermeáveis (sacos de polietileno transparente, gramatura 113,06 g/ $\mathrm{m}^{2}$ e espessura $0,11 \mathrm{~mm}$ ) e armazenadas em três condições controladas de temperatura $\left(7,15\right.$ e $\left.25^{\circ} \mathrm{C}\right)$, com umidades relativas variando de 70 a $80 \%$, nos três ambientes.

A avaliação da qualidade fisiológica, bem como a determinação do grau de umidade das sementes, foi feita no início do armazenamento (antes de serem embaladas mês zero) e após três, seis e nove meses. Para os tratamentos envolvendo frutos armazenados, imediatamente antes das avaliações, estes foram despolpados, degomados e lavados, conforme descrito anteriormente. Para a realização dos testes descritos a seguir, o pergaminho das sementes de todos os tratamentos foi retirado manualmente:

Teste de germinação: realizado com quatro repetições de 50 sementes sem pergaminho, utilizando-se como substrato, rolos de papel toalha (germitest), com três folhas embebidas com uma quantidade de água destilada equivalente a três vezes o peso do substrato seco, e colocados em germinador à temperatura de $30^{\circ} \mathrm{C}$. A avaliação foi realizada aos 15 e 30 dias após a semeadura, de acordo com as Regras para Análise de Sementes (Brasil, 1992).

Teste de envelhecimento acelerado: duzentas sementes sem pergaminho por repetição foram colocadas em caixa do tipo "gerbox", providas de tela no seu interior, contendo 40 $\mathrm{ml}$ de água destilada. $\mathrm{O}$ material foi acondicionado em uma 
estufa incubadora à $42^{\circ} \mathrm{C}$, durante 72 horas (Marcos Filho et al, 1999). Em seguida, quatro subamostras de 50 sementes por repetição foram submetidas ao teste de germinação.

Comprimento de radícula: foi utilizado como indicativo de vigor das sementes. Para isto foram utilizadas as mesmas plântulas avaliadas no teste de germinação. Após a avaliação da primeira contagem do teste de germinação, as plântulas normais foram separadas, medindo-se o comprimento de radícula. $\mathrm{O}$ resultado foi expresso pelo comprimento $(\mathrm{cm})$ médio das radículas das plântulas normais.

Determinação do grau de umidade: realizado utilizando-se sementes com pergaminho, por meio do método de estufa à $105 \pm 3^{\circ} \mathrm{C}$ durante 24 horas, conforme as prescrições das Regras para Análise de Sementes (Brasil, 1992).

O delineamento experimental utilizado foi o inteiramente casualizado, com quatro repetições. Os tratamentos foram arranjados em esquema fatorial $5 \times 2 \times 3 \times 4$, consistindo de cinco materiais (fruto cereja + sementes com 48,5, 31,5, 18,5 e $13,5 \%$ de umidade), dois tipos de embalagem (permeável e impermeável), três temperaturas de armazenamento $(25,15$ e $7^{\circ} \mathrm{C}$ ) e quatro tempos de armazenamento (zero, três, seis e nove). Em seguida, os resultados de germinação e vigor foram submetidos às análises de variância e regressão.

\section{RESULTADOS E DISCUSSÃO}

Os resultados da análise de variância dos testes de germinação, envelhecimento acelerado e comprimento de radícula indicaram significância da interação tempo de armazenamento $\mathrm{x}$ temperatura de armazenamento $\mathrm{x}$ embalagem $\mathrm{x}$ material $(\mathrm{P} \leq 0,01)$. Portanto, realizou-se a análise de variância das regressões estabelecendo-se o ajuste de regressão linear apenas dos desdobramentos dessa interação.

Pelos resultados obtidos no teste de germinação (Tabela 1), verifica-se que os tratamentos em que foram utilizados frutos cereja e aqueles que a temperatura de armazenamento foi de $25^{\circ} \mathrm{C}$ provocaram uma rápida perda na viabilidade de sementes de café. Para todos os tratamentos compostos por uma dessas duas variáveis, já aos três meses de armazenamento a germinação se encontrava abaixo de $15 \%$ e aos seis meses apresentava-se praticamente nula. Estes resultados entraram na análise estatística, entretanto, para facilitar a visualização do efeito interativo dos demais tratamentos, os dados envolvendo frutos cereja e temperatura de armazenamento de $25^{\circ} \mathrm{C}$ não foram apresentados no estudo de regressão.

A tentativa de armazenar sementes dentro dos frutos foi baseada no fato de que segundo estudos de alguns autores (Bacchi, 1955 e 1956; Ellis et al., 1990), a principal causa da rápida perda do poder germinativo de sementes de café é a grande sensibilidade destas à desidratação. Além disso, sugeria-se a hipótese de que sementes originadas de frutos despolpados poderiam sofrer algum tipo de dano mecânico e/ou algum efeito fisiológico ou químico quando em contato com o ar ambiente, vindo a provocar um efeito latente durante o armazenamento sobre a germinação e o vigor. Portanto, esperava-se que se mantendo próximas às condições em que as sementes se encontravam no campo por ocasião da colheita, ou seja, dentro dos frutos no estádio cereja, as mesmas pudessem manter o seu poder germinativo por um maior tempo. Porém, nos tratamentos em que os frutos permaneceram com alta umidade e com mucilagem, a temperatura mais alta de armazenamento $\left(25^{\circ} \mathrm{C}\right)$ favoreceu a ocorrência de fermentação, o que pôde ser observado pelo forte cheiro característico logo aos três meses de armazenamento. Certamente, a fermentação elevou ainda mais a temperatura da massa, o que ocasionou uma queda drástica na germinação e no vigor das sementes. Nos tratamentos com frutos envolvendo outras temperaturas de armazenamento $\left(15\right.$ e $\left.7^{\circ} \mathrm{C}\right)$ não foi evidenciado o processo de fermentação. Entretanto, principalmente nos tratamentos envolvendo a temperatura de $7^{\circ} \mathrm{C}$, após o despolpamento dos frutos armazenados, verificou-se que as sementes apresentavam-se mais escuras que o normal. Possivelmente houve algum tipo de dano fisiológico (dano por frio), que ocasionou a perda do poder germinativo das sementes.

Pelos resultados obtidos com a temperatura de $25^{\circ} \mathrm{C}$ torna-se claro, pelo efeito maléfico causado na germinação (Tabela 1), que essa temperatura é extremamente alta para o armazenamento de sementes de café.

Nos trabalhos até então realizados, verifica-se uma maior importância dada aos estudos envolvendo umidade inicial de sementes interagindo com o tipo de embalagem e a umidade relativa do ambiente. Embora de importância um pouco menor do que o teor de umidade, a temperatura do ar pode também desempenhar um papel de grande importância na conservação da qualidade das sementes durante o armazenamento. As sementes variam quanto às condições ideais de armazenamento. A grande maioria das espécies terá suas sementes tanto melhor conservadas quanto menor for a temperatura do ar de armazenamento e o seu grau de umidade (sementes ortodoxas). Existe, porém, sementes de espécies como o cacau e a seringueira que são denominadas recalcitrantes, que exigem grau de umidade e/ou temperatura de armazenamentos elevados 
para a sua conservação. A inclusão das sementes de café como sendo do tipo recalcitrante (Roberts, 1973) ainda gera dúvida entre os tecnologistas de sementes. Em trabalho com armazenamento de sementes de café, Ellis et al. (1990) observaram que essas sementes poderiam satisfazer tanto o conceito de recalcitrantes como o de ortodoxas, onde são incluídas as sementes da maioria das espécies, ou ainda possibilitar a criação de uma nova categoria intermediária. Pelos resultados obtidos neste trabalho, o fato de as sementes do café não ter suportado temperatura de $25^{\circ} \mathrm{C}$, independente do seu acondicionamento, descaracteriza a possibilidade de serem classificadas como recalcitrantes.

TABELA 1. Germinação (\%) e grau de umidade (\%) de sementes de café, em função de frutos e sementes armazenadas com diferentes graus de umidade, em diferentes embalagens, temperaturas e tempo de armazenamento.

\begin{tabular}{|c|c|c|c|c|c|c|}
\hline \multirow{2}{*}{$\begin{array}{c}\text { Semente (Umidade } \\
\text { Inicial em \%) ou } \\
\text { Fruto }\end{array}$} & \multirow{2}{*}{$\begin{array}{c}\text { Tipo de } \\
\text { Embalagem }\end{array}$} & \multirow{2}{*}{$\begin{array}{l}\text { Temperatura de } \\
\text { Armazenamento } \\
\left({ }^{\circ} \mathrm{C}\right)\end{array}$} & \multicolumn{4}{|c|}{$\begin{array}{l}\text { Tempo de Armazenamento } \\
\text { (meses) }\end{array}$} \\
\hline & & & 0 & 3 & 6 & 9 \\
\hline \multirow{6}{*}{ Semente $(48,5 \%)$} & \multirow[t]{3}{*}{ Permeável } & 7 & $94(48,5)^{*}$ & $77(14,3)$ & $64(14,2)$ & $49(14,4)$ \\
\hline & & 15 & $94(48,5)$ & $87(14,8)$ & $80(14,5)$ & $64(14,6)$ \\
\hline & & 25 & $94(48,5)$ & $14(14,5)$ & $3(14,6)$ & $0(14,7)$ \\
\hline & \multirow{3}{*}{ Impermeável } & 7 & $94(48,5)$ & $67(49,2)$ & $45(48,6)$ & $9(49,1)$ \\
\hline & & 15 & $94(48,5)$ & $35(48,7)$ & $12(48,5)$ & $0(48,4)$ \\
\hline & & 25 & $94(48,5)$ & $13(48,9)$ & $0(48,3)$ & $0(-)$ \\
\hline \multirow{6}{*}{ Semente $(31,5 \%)$} & \multirow{3}{*}{ Permeável } & 7 & $93(31,5)$ & $89(14,4)$ & $86(14,3)$ & $81(14,3)$ \\
\hline & & 15 & $93(31,5)$ & $81(14,7)$ & $69(14,6)$ & $23(14,4)$ \\
\hline & & 25 & $93(31,5)$ & $14(14,5)$ & $3(14,4)$ & $0(14,6)$ \\
\hline & \multirow{3}{*}{ Impermeável } & 7 & $93(31,5)$ & $79(31,6)$ & $68(31,4)$ & $45(31,6)$ \\
\hline & & 15 & $93(31,5)$ & $83(31,8)$ & $71(31,7)$ & $34(31,4)$ \\
\hline & & 25 & $93(31,5)$ & $10(32,1)$ & $0(31,8)$ & $0(-)$ \\
\hline \multirow{6}{*}{ Semente $(18,5 \%)$} & \multirow{3}{*}{ Permeável } & 7 & $91(18,5)$ & $89(14,3)$ & $88(14,4)$ & $85(14,3)$ \\
\hline & & 15 & $91(18,5)$ & $76(14,5)$ & $49(14,6)$ & $7(14,6)$ \\
\hline & & 25 & $91(18,5)$ & $10(14,6)$ & $0(14,5)$ & $0(-)$ \\
\hline & \multirow{3}{*}{ Impermeável } & 7 & $91(18,5)$ & $91(18,4)$ & $88(18,3)$ & $88(18,5)$ \\
\hline & & 15 & $91(18,5)$ & $84(18,8)$ & $78(18,5)$ & $61(18,7)$ \\
\hline & & 25 & $91(18,5)$ & $9(18,6)$ & $0(18,7)$ & $0(-)$ \\
\hline \multirow{6}{*}{ Semente $(13,5 \%)$} & \multirow{3}{*}{ Permeável } & 7 & $90(13,5)$ & $76(14,1)$ & $48(14,3)$ & $15(14,4)$ \\
\hline & & 15 & $90(13,5)$ & $66(14,3)$ & $43(14,4)$ & $13(14,5)$ \\
\hline & & 25 & $90(13,5)$ & $11(14,2)$ & $0(14,6)$ & $0(-)$ \\
\hline & \multirow{3}{*}{ Impermeável } & 7 & $90(13,5)$ & $80(13,6)$ & $50(13,7)$ & $17(13,5)$ \\
\hline & & 15 & $90(13,5)$ & $64(13,4)$ & $39(13,4)$ & $8(13,6)$ \\
\hline & & 25 & $90(13,5)$ & $10(13,6)$ & $0(13,5)$ & $0(-)$ \\
\hline \multirow{6}{*}{$\begin{array}{l}\text { Fruto Cereja } \\
\text { (recém-colhido) }\end{array}$} & \multirow{3}{*}{ Permeável } & 7 & $95(51,0)$ & $7(19,7)$ & $0(-)$ & $0(-)$ \\
\hline & & 15 & $95(51,0)$ & $12(20,2)$ & $0(-)$ & $0(-)$ \\
\hline & & 25 & $95(51,0)$ & $6(20,7)$ & $0(-)$ & $0(-)$ \\
\hline & \multirow{3}{*}{ Impermeável } & 7 & $95(51,0)$ & $6(50,8)$ & $0(-)$ & $0(-)$ \\
\hline & & 15 & $95(51,0)$ & $9(50,6)$ & $0(-)$ & $0(-)$ \\
\hline & & 25 & $95(51,0)$ & $5(50,9)$ & $0(-)$ & $0(-)$ \\
\hline
\end{tabular}

* Germinação (Grau de umidade) 
Os tratamentos que utilizaram sementes com graus de umidade inicial de 13,5\% apresentaram, depois dos tratamentos com frutos, os piores resultados de germinação, ao longo do armazenamento (Tabela 1 e Figura 1). Esses resultados podem ter ocorrido devido ao processo de secagem complementar utilizado. Apesar da temperatura de secagem ter permanecido dentro dos limites recomendados para sementes $\left(38^{\circ} \mathrm{C}\right)$, a possível sensibilidade das sementes de café à desidratação rápida pode ter provocado algum tipo de dano nas sementes.

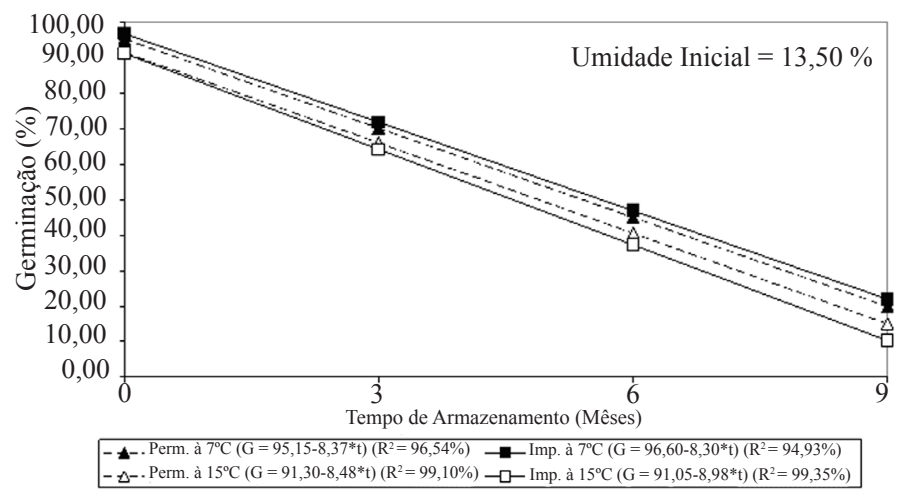

FIGURA 1. Germinação (\%) de sementes de café armazenadas com umidade inicial de $\mathbf{1 3 , 5}$ $\%$, em função do tipo de embalagem e da temperatura de armazenamento.

Os resultados das interações dos demais tratamentos obtidos neste trabalho evidenciam ainda mais as controvérsias relacionadas às condições ideais para o armazenamento de sementes de café. Contrariamente aos resultados obtidos por vários autores, os quais recomendam que as melhores condições para armazenar sementes de café são aquelas que conseguem manter a umidade das sementes acima de 30\% (Valio, 1976; Vossen, 1979; Silva \& Dias, 1985; Barboza \& Herrera, 1990 e Dias \& Barros, 1993) ou abaixo de $11 \%$ (Bacchi, 1958 e Miglioranza, 1982), neste trabalho, verificouse condições intermediárias a essas.

Verifica-se, comparando os resultados estimados de germinação apresentados nas Figuras 1 a 4, que as sementes conservaram-se melhor quando armazenadas com $18,5 \%$ de umidade (Figura 2), em ambiente com temperatura mais baixa $\left(7^{\circ} \mathrm{C}\right)$, independente da embalagem. Também, sementes com $31,5 \%$ de umidade podem ser armazenadas por nove meses, a $7^{\circ} \mathrm{C}$, quando acondicionadas em embalagem permeável (Figura 3). Estes foram os únicos tratamentos que mantiveram as sementes com germinação acima de $80 \%$, após nove meses de armazenamento. Em todos os tratamentos que utilizaram embalagem permeável, os valores de umidade das sementes entraram em equilíbrio higroscópico com o ambiente ao longo dos três primeiros meses de armazenamento e se mantiveram constantes, em torno de $14,5 \%$, até o final do experimento (Tabela 1). No tratamento que foi utilizado embalagem impermeável, a umidade inicial (18,5\%), também se manteve constante (Tabela 1). Portanto, sementes de café que não foram submetidas a processo de secagem artificial complementar (desidratação rápida), e sim, apenas à sombra, e armazenadas com umidade, após equilíbrio higroscópico, de 14,5 a $18,5 \%$, em temperatura de $7^{\circ} \mathrm{C}$, mantiveram seu poder germinativo acima de $80 \%$, por um período satisfatório (nove meses).

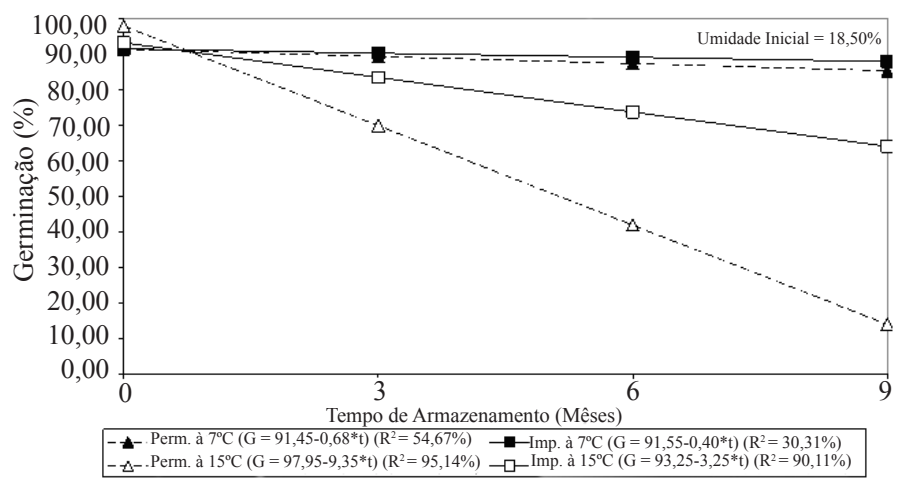

FIGURA 2. Germinação (\%) de sementes de café armazenadas com umidade inicial de 18,5 $\%$, em função do tipo de embalagem e da temperatura de armazenamento.

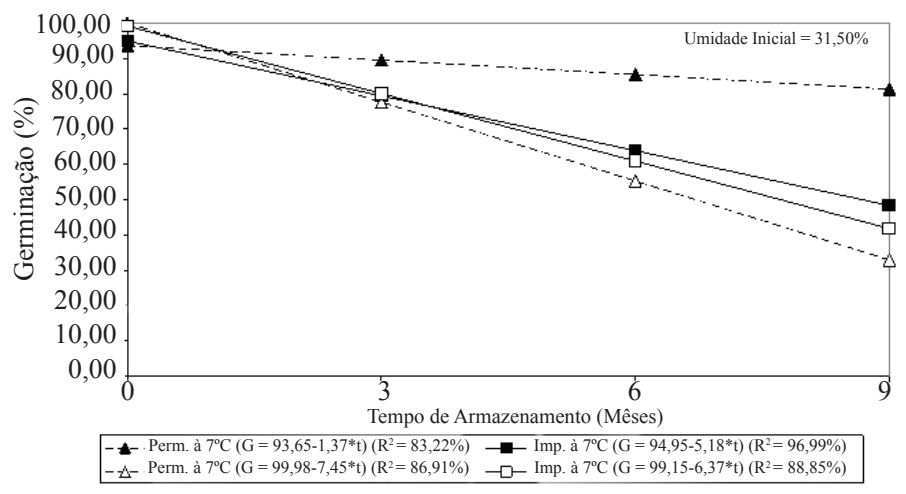

FIGURA 3. Germinação (\%) de sementes de café armazenadas com umidade inicial de $\mathbf{3 1 , 5}$ $\%$, em função do tipo de embalagem e da temperatura de armazenamento. 
Como os padrões de produção de sementes básicas de café em Minas Gerais exigem germinação mínima de 70\% (IMA, 2001), os tratamentos mencionados acima podem ser considerados bem eficientes.

Os resultados obtidos por Miranda \& Valias (1984) concordam e discordam, em parte, com os resultados comentados anteriormente. De acordo com esses autores, sementes armazenadas com $16 \%$ de umidade, em saco de papel multifoliado (embalagem permeável), apresentaram redução sensível na germinação a partir do quarto mês de armazenamento. Esses resultados discordam dos obtidos neste trabalho, os quais demonstraram que sementes com $18,5 \%$ de umidade inicial, acondicionadas em sacos de pano e armazenadas em temperatura de $7^{\circ} \mathrm{C}$, mantiveram seu poder germinativo acima de $80 \%$ por nove meses. Entretanto, esses mesmos autores, utilizando o mesmo grau de umidade das sementes $(16 \%)$, em condição hermética, obtiveram bons resultados após nove meses de armazenamento, o que concorda com o obtido neste experimento, quando as sementes foram acondicionadas com $18,5 \%$ de umidade em sacos de polietileno e conservadas a $7^{\circ} \mathrm{C}$.

Vasconcelos et al. (1992) obtiveram os melhores resultados na manutenção da qualidade fisiológica quando as sementes de café foram armazenadas com $35 \%$ de umidade em sacos de polietileno liso. Ainda, segundo os mesmos autores, sementes com 15 e $22 \%$ de umidade e acondicionadas em sacos de aniagem apresentaram redução significativa na germinação e no vigor a partir do quarto mês de armazenamento. Estes resultados discordam com os obtidos neste trabalho, já que o ambiente de armazenamento não era controlado. A variação da umidade relativa e da temperatura do ambiente de armazenamento pode interferir, sobremaneira, nas sementes armazenadas em embalagens permeáveis, dificultando a comparação dos resultados entre experimentos.

Como comentado anteriormente, de acordo com as condições ideais de armazenamento as sementes podem ser denominadas ortodoxas ou recalcitrantes. Entretanto, resultados de diversos trabalhos (Ellis et al., 1990; Ellis, 1991 e Hong \& Ellis, 1992 e 1995) têm evidenciado um comportamento intermediário das sementes de café, o que concorda com os melhores resultados deste trabalho, reforçando a possibilidade de haver uma terceira categoria de sementes. Essa suposição ainda pode ser reforçada pelos resultados obtidos nos tratamentos com os maiores graus de umidade inicial das sementes (48,5 e 31,5\%) (Figuras 3 e 4). Nestes tratamentos, quando foi utilizada embalagem impermeável, a umidade foi mantida alta e constante (Tabela 1) e os resultados de germinação foram, de modo geral, inferiores àqueles obtidos nos tratamentos com os mesmos graus de umidade com o uso de embalagem permeável, a qual permitiu que a umidade das sementes decrescesse e entrasse em equilíbrio higroscópico com o ambiente (Tabela 1).

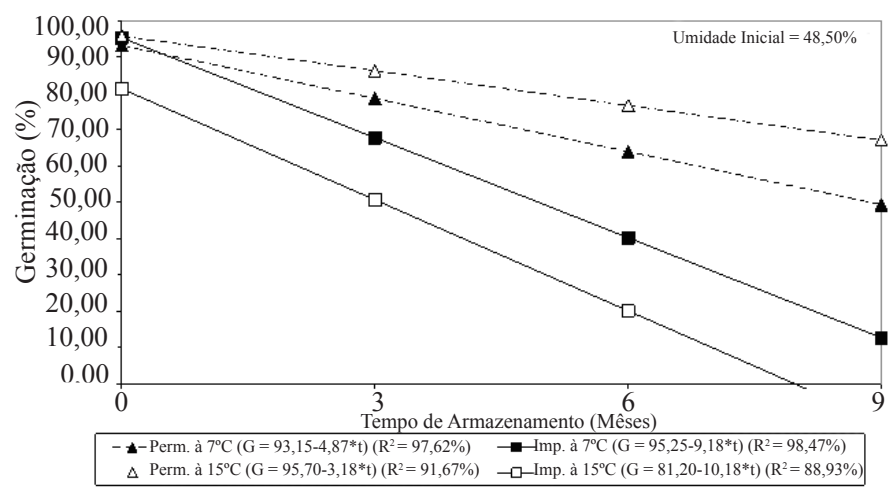

FIGURA 4. Germinação (\%) de sementes de café armazenadas com umidade inicial de 48,5 $\%$, em função do tipo de embalagem e da temperatura de armazenamento

Os resultados de vigor obtidos pelo teste de envelhecimento acelerado e pelo comprimento radicular, medido no teste de germinação, revelaram a mesma tendência dos resultados de germinação. Portanto, para não tornar repetitiva a discussão, optou-se por não apresentar esses resultados.

\section{CONCLUSÕES}

Nas condições em que o trabalho foi conduzido, os resultados permitiram concluir que:

- sementes de café conservam-se melhor quando armazenadas com $18,5 \%$ de umidade inicial, em ambiente de baixa temperatura $\left(7^{\circ} \mathrm{C}\right)$, independente da embalagem;

- sementes com $31,5 \%$ de umidade também podem ser armazenadas por nove meses a $7^{\circ} \mathrm{C}$, quando acondicionadas em embalagem permeável;

- com umidade ainda mais elevada (48,5\%), as sementes conservam-se bem até o sexto mês de armazenamento, quando acondicionadas em embalagem permeável e em temperatura de $15^{\circ} \mathrm{C}$;

- frutos armazenados nas diversas temperaturas e sementes a $25^{\circ} \mathrm{C}$, apresentam queda drástica na germinação e no vigor já aos três meses de armazenamento.

\section{AGRADECIMENTO}

À Fundação de Amparo à Pesquisa do Estado de Minas Gerais (FAPEMIG) pela concessão da bolsa de pesquisa ao 
primeiro autor.

\section{REFERÊNCIAS}

ARAUJO, R.F. Influência do teor de umidade, da embalagem e do ambiente de armazenamento na conservação de sementes de café (Coffea arabica L.). 1988. 56f. Dissertação (Mestrado em Fitotecnia) - Universidade Federal de Viçosa, Viçosa, 1988.

BACCHI, O. Seca da semente de café ao sol. Bragantia, Campinas, v.14, n.22, p.225-236, 1955.

BACCHI, O. Novos ensaios sobre a seca da semente de café ao sol. Bragantia, Campinas, v.15, n.8, p.83-91, 1956.

BACCHI, O. Estudos sobre a conservação de sementes: café. Bragantia, Campinas, v.17, n.20, p.261-270, 1958.

BARBOZA, R.; HERRERA, J. El vigor em la semilla de cafe y su relacion com la temperatura de secado, el contenido de humedad y las condiciones de almacenamiento. Agronomia Costarricense, San José, v.14, n.1, p.1-8, 1990.

BENDANÃ, F.E. Fisiologia de las semillas de cafe: problemas relativos al almacenamiento. Turrialba, San José, v.4, n.15, p.93-96, 1962.

BRASIL, Ministério da Agricultura e Reforma Agrária. Regras para análise de sementes. Brasília: DNDV/SNAD/ CLAV, 1992. 365p.

DIAS, M.C.L.L.; BARROS, A.S.R. Conservação de sementes de café (Coffea arabica L.) em diferentes embalagens. Revista Brasileira de Sementes, Brasília, v.15, n.2, p.197202, 1993.

ELLIS, R.H. The longevity of seeds. HortScience, Alexandria, v.26, n.9, p.1119-1125, 1991.

ELLIS, R.H.;HONG, T.D.; ROBERTS, E.H. An intermediate category of seed storage behaviour? I. Coffee. Journal of Experimental Botany, Oxford, v.41, n.230, p.1167-1174, 1990.

HONG, T.D.; ELLIS, R.H. Optimum air-dry seed storage environments for Arabica coffee. Seed Science \& Technology, Zürich, v.20, p.547-560, 1992.

HONG, T.D.; ELLIS, R.H. Interspecific variation in seed storage behaviour within two genera - Coffea and Citrus.
Seed Science \& Technology, Zürich, v.23, n.1, p.165-181, 1995.

IMA - Instituto Mineiro de Agropecuária. Portaria $N^{\circ} 482$, de 29 de novembro de 2001. Dispõe sobre normas e padrões para a produção de sementes básicas e fiscalizadas e de mudas fiscalizadas de café. Diário Oficial do Estado de Minas Gerais. Belo Horizonte, MG, 2001. Disponível em: $<$ http://www.ima.mg.gov.br/site_ima/ legislação/portarias_ pdf/0482\%20.pdf>. Acesso em: 22/03/2007.

MARCOS FILHO, J. Teste de envelhecimento acelerado. In: KRZYZANOWSKI, F.C.; VIEIRA, R.D., FRANÇA NETO, J.B. (Eds). Vigor de sementes: conceitos e testes. Londrina: Associação Brasileira de Tecnologia de Sementes, 1999. Cap. 3, p.1-24.

MIGLIORANZA, E. Conservação de sementes de café ( $\boldsymbol{C}$. arabica, L. cv. Catuai) com diferentes teores de umidade, armazenadas em ambientes hermeticamente fechados. 1982. 60f. Dissertação (Mestrado em Fitotecnia) - Escola Superior de Agricultura Luiz de Queiroz, USP, Piracicaba, 1982.

MIRANDA, J.M.; VALIAS, E.P. Estudo sobre a conservação da viabilidade de sementes de café. In: CONGRESSO BRASILEIRO DE PESQUISAS CAFEEIRAS, 11., 1984, Londrina. Resumos... Rio de Janeiro: Ministério da Indústria e do Comércio, IBC, 1984. p.160-161.

ROBERTS, E.H. Predicting the storage life of seeds. Seed Science \& Technology, Zürich, v.1, n.3, p.499-514, 1973.

SILVA, W.R. \& DIAS, M.C.L.L. Interferência do teor de umidade das sementes de café na manutenção de sua qualidade fisiológica. Pesquisa Agropecuária Brasileira, Brasília, v.20, n.5, p.551-560, 1985.

VALIO, I.F.M. Germination of coffee seeds, (Coffea arabica L. cv. Mundo Novo). Journal of Experimental Botany, v.27, n.100, p.983-991, 1976.

VASCONCELOS, L.M.; GROTH, D. \& RAZERA, L.F. Efeito de processos de secagem, diferentes graus de umidade e tipos de embalagens na conservação de sementes de café (Coffea arábica L. cv. Catuaí Vermelho). Revista Brasileira de Sementes, Brasília, v.14, n.2, p.181-188, 1992.

VOSSEN, H.A.M.van der. Methods of preserving the viability of coffee seed in storage. Seed Science \& Technology, Zürich, v.7, n.1, p.65-74, 1979. 